\title{
Nonporous Adaptive Calix[4]pyrrole Crystals for Polar Compound Separations
}

\author{
Dan Luo,$^{\dagger}$ Jinya Tian, ${ }^{\dagger}$ Jonathan L. Sessler, ${ }^{*}+$ and Xiaodong Chi ${ }^{*}, \dagger$ \\ ${ }^{\dagger}$ State Key Laboratory of Materials Processing and Die \& Mould Technology, School of Materials Science \\ and Engineering, Huazhong University of Science and Technology, Wuhan 430074, China \\ *Department of Chemistry, The University of Texas at Austin, 105 E. 24th Street, Stop A5300, Austin, \\ Texas 78712-1224, USA.
}

\section{Supporting Information}

1. Materials and methods $\quad S 2$

2. Synthesis and characterization of $\mathbf{C 4 P} S 3$

3. X-ray experimental data for $\mathbf{C 4 P}$ and Py@C4P S6

4. $\mathrm{N}_{2}$ adsorption isotherm of $\boldsymbol{C 4 P} \quad S 10$

5. Powder X-ray diffraction patterns $\quad S 10$

6. Single-component Tol/Py adsorption experiments $\quad S 12$

7. Uptake from a toluene/pyridine mixture by $\boldsymbol{C 4 P} \quad S 13$

8. Dioxane removal from a dioxane/water mixture by $\mathbf{C 4 P} \quad S 19$

9. Recyclability of $\mathbf{C 4 P} \quad S 21$

10. References S24 


\section{Materials and methods}

All reagents, including toluene (Tol) and pyridine (Py), were purchased commercially and used without further purification. One-dimensional nuclear magnetic resonance (NMR) spectra were recorded on a Varian 400 spectrometer. Chemical shifts are reported in ppm relative to TMS, which was used as an internal reference. Low-resolution electrospray ionization mass spectra were recorded with an Ion Spec Fourier Transform mass spectrometer (9.4 T). Activated crystalline C4P was recrystallized from acetone / water mixture and dried under vacuum at $80^{\circ} \mathrm{C}$ overnight. Powder X-ray diffraction (PXRD) data were collected on a Rigaku Ultimate-IV X-ray diffractometer operating at $40 \mathrm{kV} / 30 \mathrm{~mA}$ using the $\mathrm{Cu} \mathrm{K}_{\alpha}$ line $(\lambda=1.5418 \AA)$. Data were measured over the range of $5-50^{\circ}$ in $5^{\circ} / \mathrm{min}$ steps over $9 \mathrm{~min}$. Thermogravimetric analyses (TGA) were carried out using a Q5000IR analyzer (TA Instruments) with an automated vertical overhead thermobalance. The samples were heated at $10{ }^{\circ} \mathrm{C} / \mathrm{min}$ using $\mathrm{N}_{2}$ as the protective gas. Single crystal X-ray diffraction data were collected on a Rigaku XtaLAB PRO MM007HF X-ray diffractometer with graphite monochromated $\mathrm{Cu} \mathrm{K} \alpha$ radiation. Low-pressure gas adsorption measurements were performed on a Micrometritics Accelerated Surface Area and Porosimetry System (ASAP) 2020 surface area analyzer. Samples were degassed under dynamic vacuum for $12 \mathrm{~h}$ at $110{ }^{\circ} \mathrm{C}$ prior to each measurement. $\mathrm{N}_{2}$ isotherms were measured using a liquid nitrogen bath $(77 \mathrm{~K})$. Gas chromatographic (GC) measurements were carried out using an Agilent 7890B instrument configured with an Agilent 19091S-433 detector and a HP-5MS column $(30 \mathrm{~m} \times 250 \mu \mathrm{m} \times 0.25$ $\mu \mathrm{m})$. Samples were analyzed using headspace injections and were performed by incubating the sample (dissolved in glycerol 1,2-diacetate) at $70{ }^{\circ} \mathrm{C}$ for $10 \mathrm{~min}$ followed by sampling $1 \mathrm{~mL}$ of the headspace. The following GC method was used: the oven was programmed from $50{ }^{\circ} \mathrm{C}$, and ramped in $10{ }^{\circ} \mathrm{C} \mathrm{min}-1$ increments to $150{ }^{\circ} \mathrm{C}$ with a 10 min hold; the total run time was $23.5 \mathrm{~min}$; the injection temperature was $250{ }^{\circ} \mathrm{C}$; the detector temperature was $280{ }^{\circ} \mathrm{C}$ with nitrogen, air, and make-up flow-rates of 35,350 , and $35 \mathrm{~mL} \mathrm{~min}^{-1}$, respectively; the helium (carrier gas) flow rate was $3.0 \mathrm{~mL} \mathrm{~min}^{-1}$. The samples were injected in the split mode (30:1). 


\section{Synthesis and characterization of C4P}

Scheme S1. Synthesis of C4P

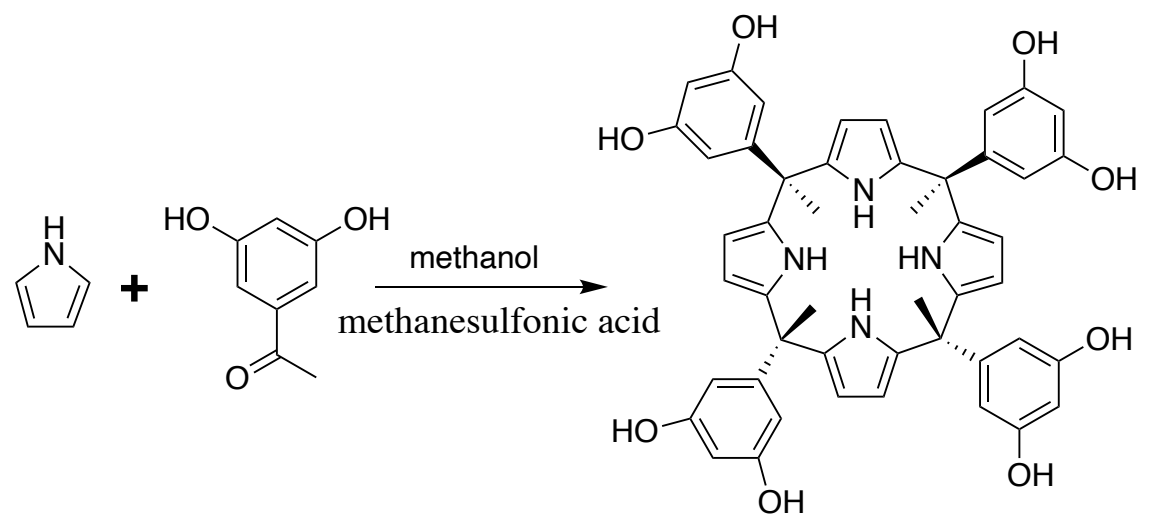

C4P: The tetra-meso functionalized C4P was obtained using a modification of standard literature method. 2,3-Dihydroxyacetophenone (7.61 g, $50 \mathrm{mmol})$, pyrrole $(3.36 \mathrm{~g}, 50 \mathrm{mmol})$, and methanesulfonic acid $(2.40 \mathrm{~g}, 25 \mathrm{mmol})$ were dissolved in methanol $(300 \mathrm{~mL})$ and stirred at room temperature for $6 \mathrm{~h}$ under an $\mathrm{N}_{2}$ atmosphere. After this mixture was neutralized with ammonia gas and passed through a short silica gel precolumn, the mixture was concentrated and recrystallized from acetic acid to afford the desired product $\mathbf{C 4 P}$ in $25 \%$ yield. The ${ }^{1} \mathrm{H}$ NMR spectrum of $\mathbf{C 4 P}$ is shown in Figure S1. ${ }^{1} \mathrm{H}$ NMR (400 MHz, DMSO- $\left.d_{6}, 25{ }^{\circ} \mathrm{C}\right) \delta(\mathrm{ppm}): 9.53(\mathrm{~s}, 2 \mathrm{H}), 9.17(\mathrm{~s}, 2 \mathrm{H})$, $8.78(\mathrm{~s}, 8 \mathrm{H}), 6.02(\mathrm{~s}, 8 \mathrm{H}), 5.97(\mathrm{~m}, 4 \mathrm{H}), 5.90(\mathrm{~m}, 4 \mathrm{H}), 5.58(\mathrm{~s}, 4 \mathrm{H}), 1.74(\mathrm{~s}, 12 \mathrm{H}) ;{ }^{13} \mathrm{C} \mathrm{NMR}(100$ $\left.\mathrm{MHz}, \mathrm{DMSO}-d_{6}, 25^{\circ} \mathrm{C}\right) \delta(\mathrm{ppm}): 159.97,151.55,138.55,137.02,105.97,103.69,100.67,99.62$, 46.24, 37.19, 31.26. 


\begin{tabular}{|c|c|c|}
\hline 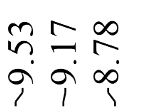 & 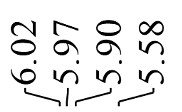 & $\stackrel{+}{m}$ \\
\hline
\end{tabular}

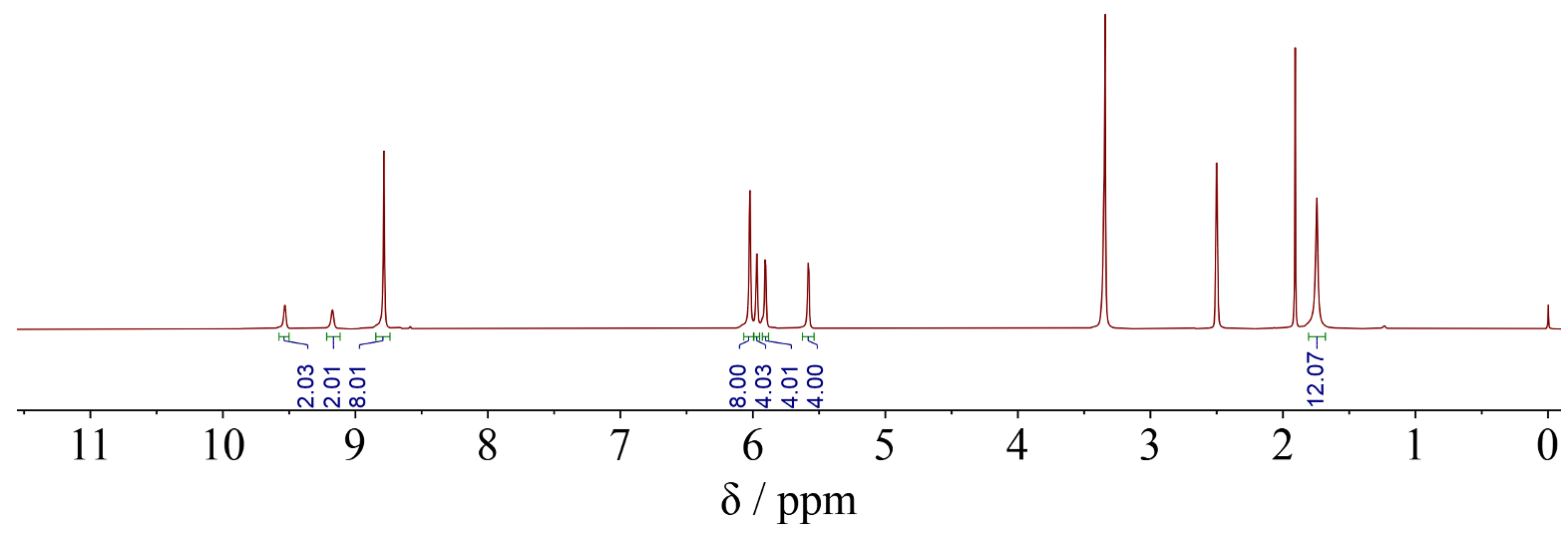

Figure S1. ${ }^{1} \mathrm{H}$ NMR spectrum $\left(400 \mathrm{MHz}, \mathrm{DMSO}-d_{6}, 25^{\circ} \mathrm{C}\right)$ of $\mathbf{C 4 P}$. 


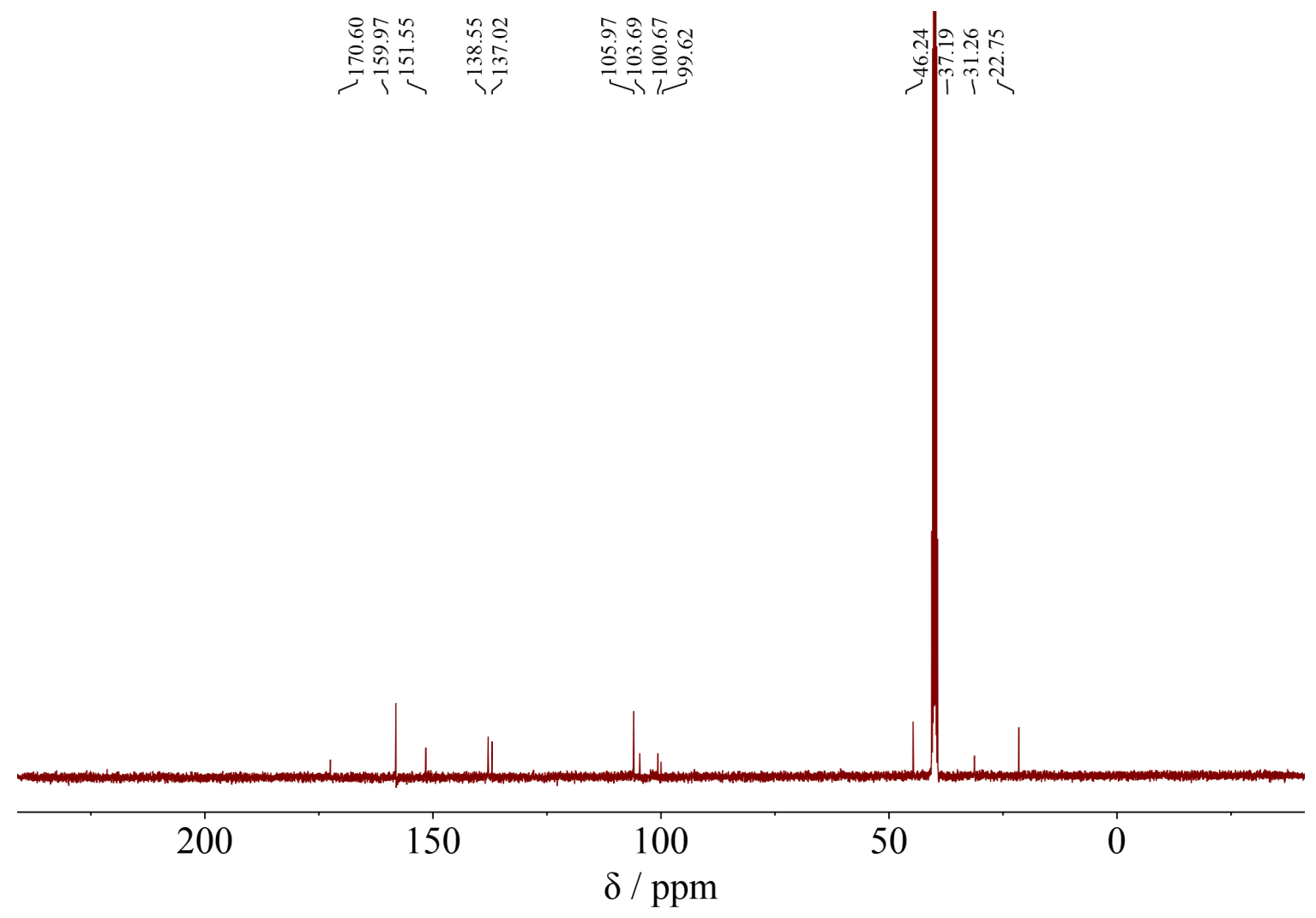

Figure S2. ${ }^{13} \mathrm{C}$ NMR spectrum $\left(100 \mathrm{MHz}\right.$, DMSO- $\left.d_{6}, 25{ }^{\circ} \mathrm{C}\right)$ of $\mathbf{C 4 P}$.

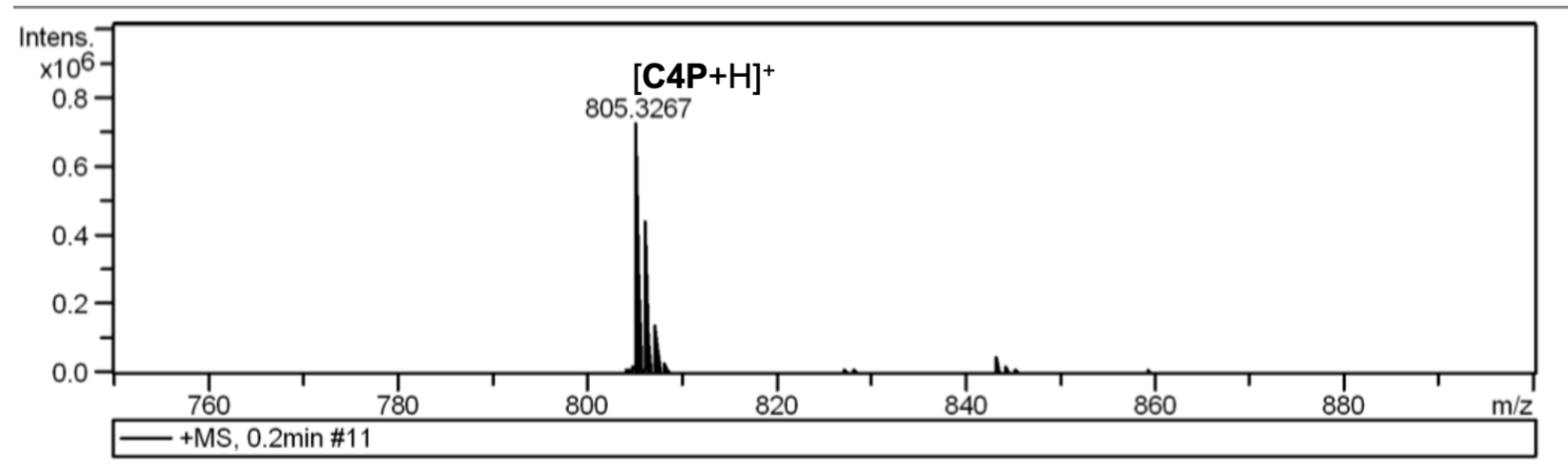

Figure S3. Electrospray ionization mass spectrum of C4P. 


\section{X-ray experimental data for C4P and Py@C4P \\ X-ray experimental for C4P (CCDC number: 2087997)}

X-ray experimental for $\mathrm{C}_{48} \mathrm{H}_{44} \mathrm{~N}_{4} \mathrm{O}_{8}-2 \mathrm{C}_{3} \mathrm{H}_{6} \mathrm{O}$ : Crystals grew as clusters of colorless plates by slow evaporation from acetone. The data crystal was cut from a cluster of crystals and had approximate dimensions; $0.31 \times 0.22 \times 0.062 \mathrm{~mm}$. The data were collected on an Agilent Technologies SuperNova Dual Source diffractometer using a $\mu$-focus $\mathrm{Cu} \mathrm{K} \alpha$ radiation source $(\lambda=$ $1.5418 \AA$ ) with collimating mirror monochromators. A total of 839 frames of data were collected using $\omega$-scans with a scan range of $1^{\circ}$ and a counting time of 5 seconds per frame for frames collected with a detector offset of $+/-42.8^{\circ}$ and 17 seconds per frame with frames collected with a detector offset of $110.8^{\circ}$. The data were collected at $100 \mathrm{~K}$ using an Oxford Cryostream low temperature device. Details of crystal data, data collection and structure refinement are listed in Table 1. Data collection, unit cell refinement and data reduction were performed using Rigaku Oxford Diffraction's CrysAlisPro V 1.171.40.53. ${ }^{1}$ The structure was solved by direct methods using SHELXT ${ }^{2}$ and refined by full-matrix least-squares on $\mathrm{F}^{2}$ with anisotropic displacement parameters for the non-H atoms using SHELXL-2016/6. ${ }^{3}$ Structure analysis was aided by use of the programs PLATON ${ }^{4}, \mathrm{OLEX}^{5}$ and WinGX. ${ }^{6}$ The hydrogen atoms on the carbon atoms were calculated in ideal positions with isotropic displacement parameters set to $1.2 \mathrm{xUeq}$ of the attached atom (1.5xUeq for methyl hydrogen atoms).

A molecule of acetone was disordered around a crystallographic inversion center at 0,0 ,

$1 / 2$. The contributions to the scattering factors due to this solvent molecule were removed by use of the utility SQUEEZE ${ }^{7}$ in PLATON. PLATON was used as incorporated in WinGX.

The function, $\Sigma \mathrm{w}\left(\left|\mathrm{F}_{\mathrm{O}}\right|^{2}-\left|\mathrm{F}_{\mathrm{C}}\right|^{2}\right)^{2}$, was minimized, where $\mathrm{w}=1 /\left[\left(\sigma\left(\mathrm{F}_{\mathrm{O}}\right)\right)^{2}+(0.0843 * \mathrm{P})^{2}+\right.$ $(0.6814 * \mathrm{P})]$ and $\mathrm{P}=\left(\left|\mathrm{F}_{\mathrm{O}}\right|^{2}+2\left|\mathrm{~F}_{\mathrm{C}}\right|^{2}\right) / 3 . \mathrm{R}_{\mathrm{W}}\left(\mathrm{F}^{2}\right)$ refined to 0.153 , with $\mathrm{R}(\mathrm{F})$ equal to 0.05366 and a goodness of fit, $\mathrm{S},=1.03$. Definitions used for calculating $\mathrm{R}(\mathrm{F}), \mathrm{R}_{\mathrm{W}}\left(\mathrm{F}^{2}\right)$ and the goodness of fit, $\mathrm{S}$, are given below. ${ }^{8}$ The data were checked for secondary extinction effects but no correction was necessary. Neutral atom scattering factors and values used to calculate the linear absorption coefficient are from the International Tables for X-ray Crystallography (1992). ${ }^{9}$ All figures were generated using SHELXTL/PC. ${ }^{10}$ 

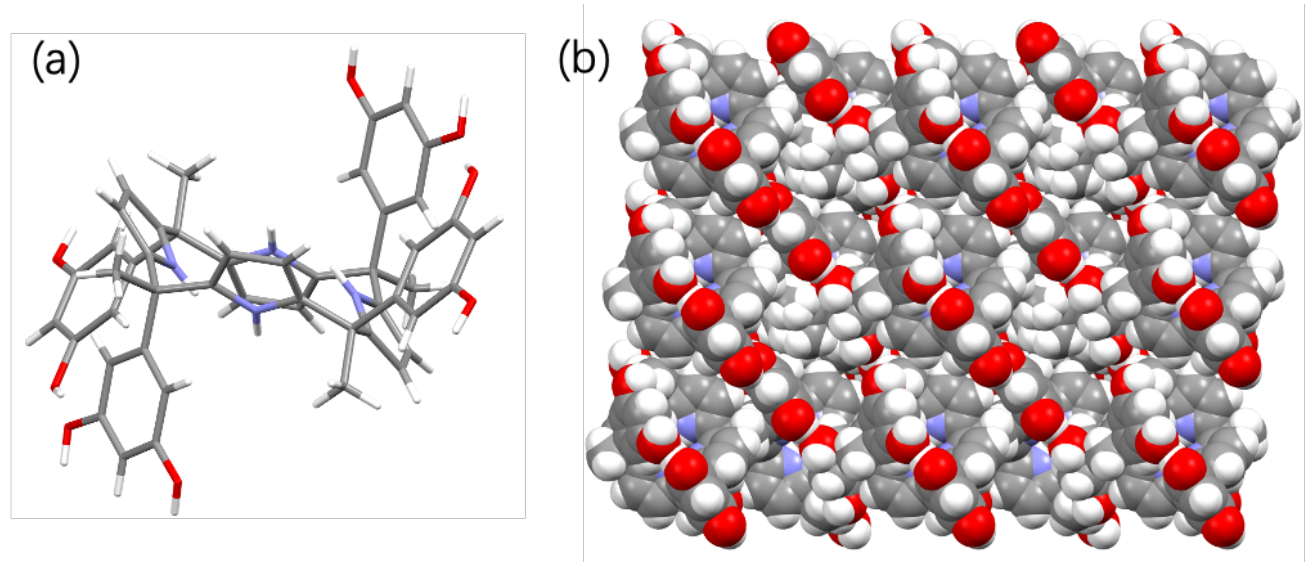

Figure S4. Single-crystal X-ray diffraction structure of C4P; solvent (acetone) in the structure was ignored. (a) Single crystal structure of $\mathbf{C 4 P}$; (b) stacking arrangement for $\mathbf{C 4 P}$ as viewed down the $\mathrm{b}$ axis.

Table S1. Single crystal X-ray data for C4P

Identification code

Empirical formula

Formula weight

Temperature

Wavelength

Crystal system

Space group

Unit cell dimensions

Volume

Z

Density (calculated)

Absorption coefficient

$\mathrm{F}(000)$

Crystal size

Theta range for data collection

Index ranges

Reflections collected

Independent reflections shelx

C54 H56 N4 O10

921.02

$100(2) \mathrm{K}$

\section{$1.54184 \AA$}

monoclinic

P 21/c

$\mathrm{a}=11.0205(3) \AA$ $\alpha=90^{\circ}$.

$\mathrm{b}=14.6719(4) \AA$ $\beta=95.979(3)^{\circ}$.

$\mathrm{c}=17.0998(6) \AA$ $\gamma=90^{\circ}$.

2749.85(14) $\AA^{3}$

2

$1.112 \mathrm{Mg} / \mathrm{m}^{3}$

$0.627 \mathrm{~mm}^{-1}$

976

$0.310 \times 0.220 \times 0.062 \mathrm{~mm}^{3}$

3.979 to $75.688^{\circ}$.

$-13<=\mathrm{h}<=13,-15<=\mathrm{k}<=18,-19<=\mathrm{l}<=21$

13350

$5522[\mathrm{R}(\mathrm{int})=0.0406]$ 
Completeness to theta $=67.684^{\circ}$

Absorption correction

Max. and min. transmission

Refinement method

Data / restraints / parameters

Goodness-of-fit on $\mathrm{F}^{2}$

Final $R$ indices [I $>2 \operatorname{sigma}(\mathrm{I})]$

$\mathrm{R}$ indices (all data)

Extinction coefficient

Largest diff. peak and hole
$99.9 \%$

Semi-empirical from equivalents

1.00 and 0.718

Full-matrix least-squares on $\mathrm{F}^{2}$

$5522 / 31 / 346$

1.034

$\mathrm{R} 1=0.0536, \mathrm{wR} 2=0.1446$

$\mathrm{R} 1=0.0622, \mathrm{wR} 2=0.1532$

$\mathrm{n} / \mathrm{a}$

0.453 and -0.375 e. $\AA^{-3}$

\section{X-ray experimental for C4P@Py (CCDC number: 2087999)}

$\mathrm{X}$-ray experimental for $\mathrm{C}_{78} \mathrm{H}_{78} \mathrm{~N}_{10} \mathrm{O}_{10}$ : Crystals grew as clusters of light yellow plates by slow evaporation from acetone/water. The data crystal was cut from a cluster of crystals and had approximate dimensions; $0.2 \times 0.15 \times 0.03 \mathrm{~mm}$. The data were collected on XtaLAB PRO MM007HF Cu Rigaku, using a $\mu$-focus $\mathrm{Cu} \mathrm{K} \alpha$ radiation source $(\lambda=1.5418 \AA)$ with collimating mirror monochromators.

Table S2. Experimental single crystal X-ray data for C4P@Py

\begin{tabular}{|c|c|}
\hline Empirical formula & $\mathrm{C}_{78} \mathrm{H}_{78} \mathrm{~N}_{10} \mathrm{O}_{10}$ \\
\hline Formula weight & 1315.50 \\
\hline Temperature/K & $100.00(10)$ \\
\hline Crystal system & triclinic \\
\hline Space group & P-1 \\
\hline $\mathrm{a} / \AA \AA$ & $10.18280(10)$ \\
\hline $\mathrm{b} / \AA \AA$ & $11.4144(2)$ \\
\hline$c / \AA ̊$ & $15.4936(2)$ \\
\hline$\alpha /^{\circ}$ & $107.5670(10)$ \\
\hline$\beta /^{\circ}$ & $97.7630(10)$ \\
\hline $\mathrm{Y} /{ }^{\circ}$ & $100.0080(10)$ \\
\hline Volume $/ \AA^{3}$ & $1656.65(4)$ \\
\hline Z & 1 \\
\hline$\rho_{\text {calc }} \mathrm{g} / \mathrm{cm}^{3}$ & 1.319 \\
\hline$\mu / \mathrm{mm}^{-1}$ & 0.714 \\
\hline$F(000)$ & 696.0 \\
\hline Crystal size $/ \mathrm{mm}^{3}$ & $0.2 \times 0.15 \times 0.03$ \\
\hline Radiation & Cu K $\alpha(\lambda=1.54184)$ \\
\hline \multicolumn{2}{|c|}{$2 \Theta$ range for data collection ${ }^{\circ} 6.106$ to 147.81} \\
\hline Index ranges & $-12 \leq h \leq 12,-14 \leq k \leq 11,-19 \leq I \leq 19$ \\
\hline Reflections collected & 17754 \\
\hline Independent reflections & $6460\left[R_{\text {int }}=0.0296, R_{\text {sigma }}=0.0337\right]$ \\
\hline Data/restraints/parameters & $6460 / 0 / 452$ \\
\hline Goodness-of-fit on $\mathrm{F}^{2}$ & 1.046 \\
\hline Final R indexes $[\mid>=2 \sigma(I)]$ & $R_{1}=0.0388, w R_{2}=0.0997$ \\
\hline Final $R$ indexes [all data] & $\mathrm{R}_{1}=0.0447, w \mathrm{R}_{2}=0.1029$ \\
\hline Largest diff. peak/hole / e $\AA^{-3}$ & $30.28 /-0.28$ \\
\hline
\end{tabular}




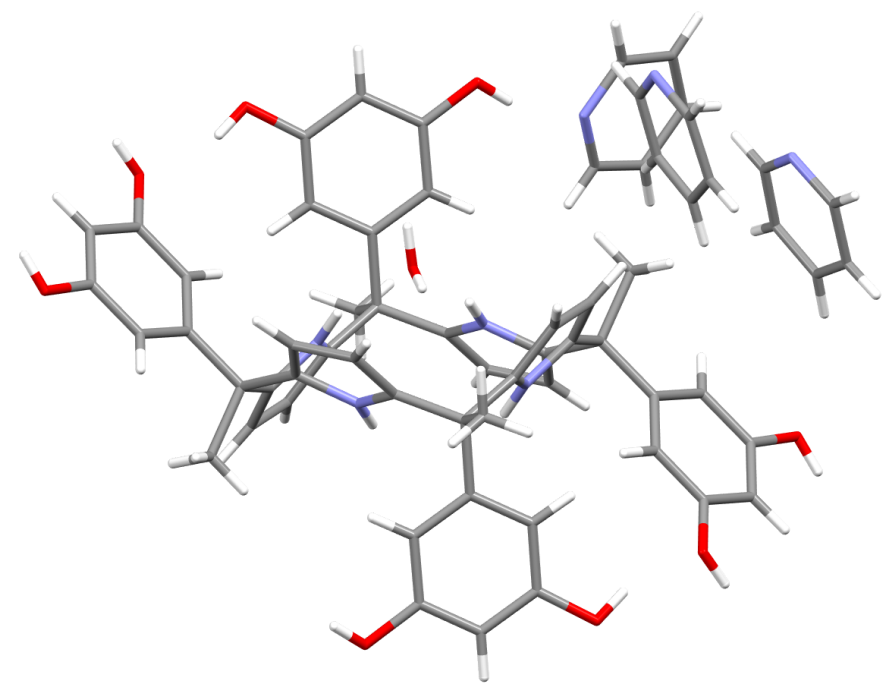

Figure S5. Single crystal structure of Py@ C4P

(a)

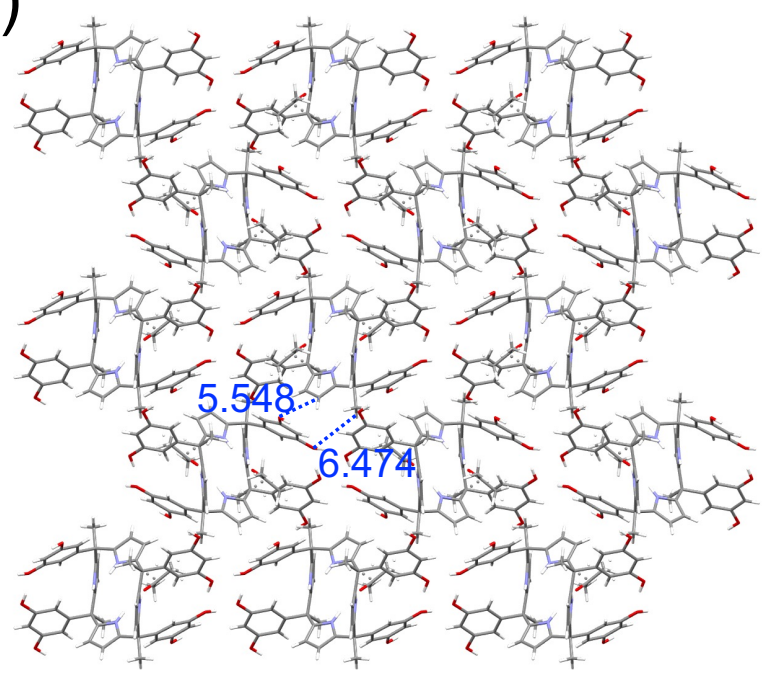

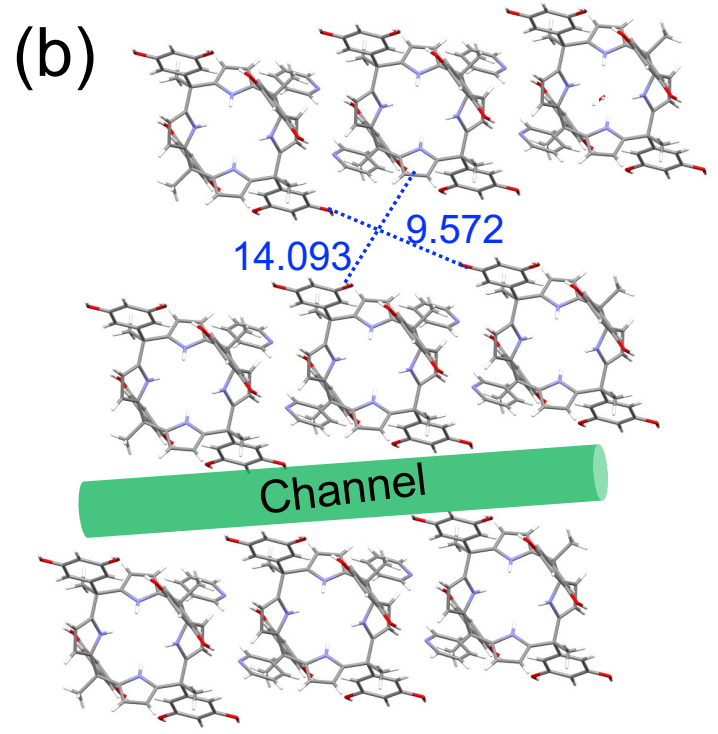

Figure S6. Single crystal structures show distance between two individual C4P subunit: (a) C4P alone; (b) Py@C4P. Acetone solvent and pyridine have been omitted for clarity. 


\section{4. $\mathbf{N}_{2}$ adsorption isotherm for $\mathbf{C} 4 \mathbf{P}$}

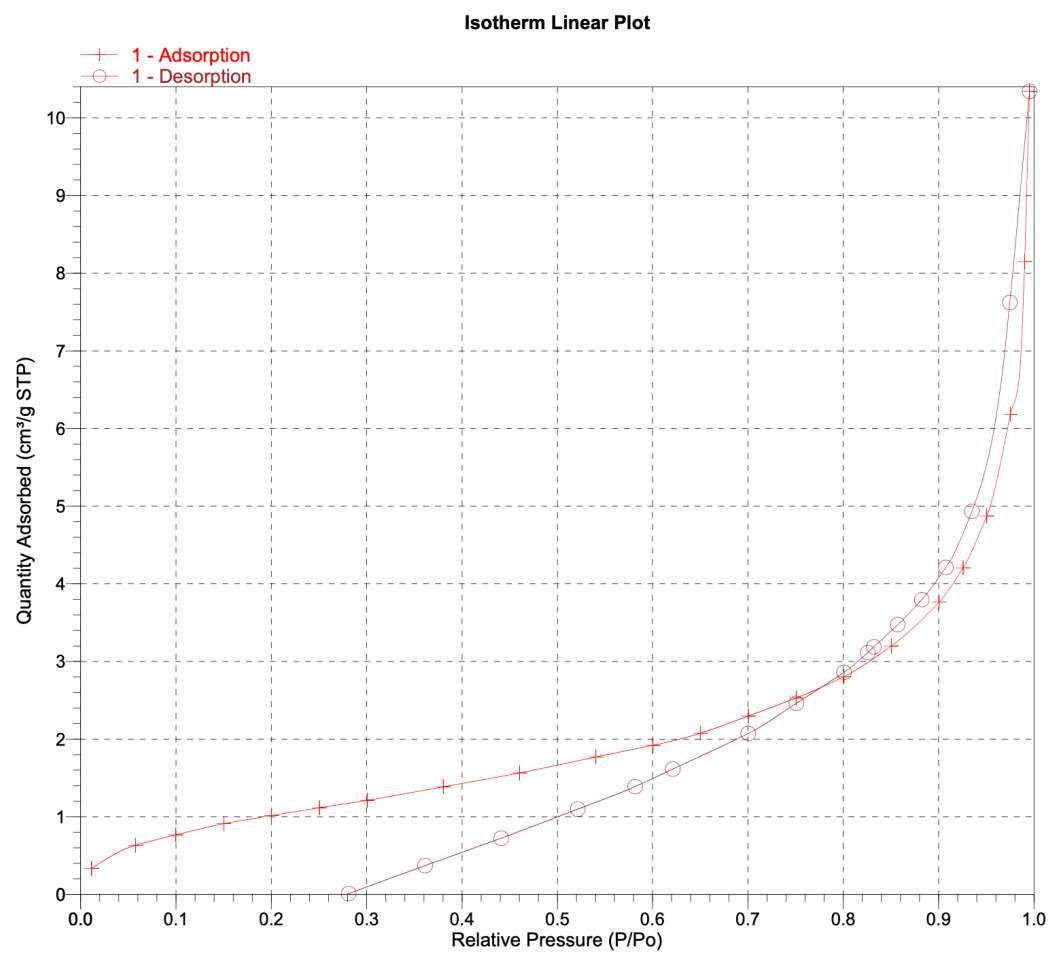

Figure S7. $\mathrm{N}_{2}$ adsorption isotherm for C4P. The BET surface area value is $3.84 \mathrm{~m}^{2} / \mathrm{g}$. 


\section{Powder X-ray diffraction patterns}

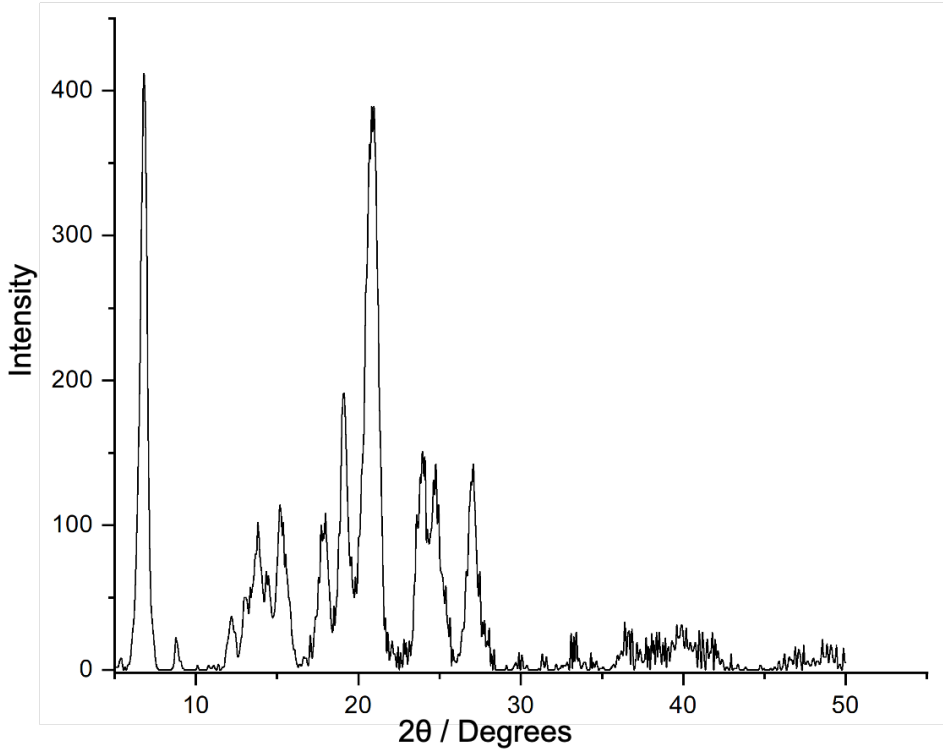

Figure S8. Powder X-ray diffraction pattern of C4P prior to activation

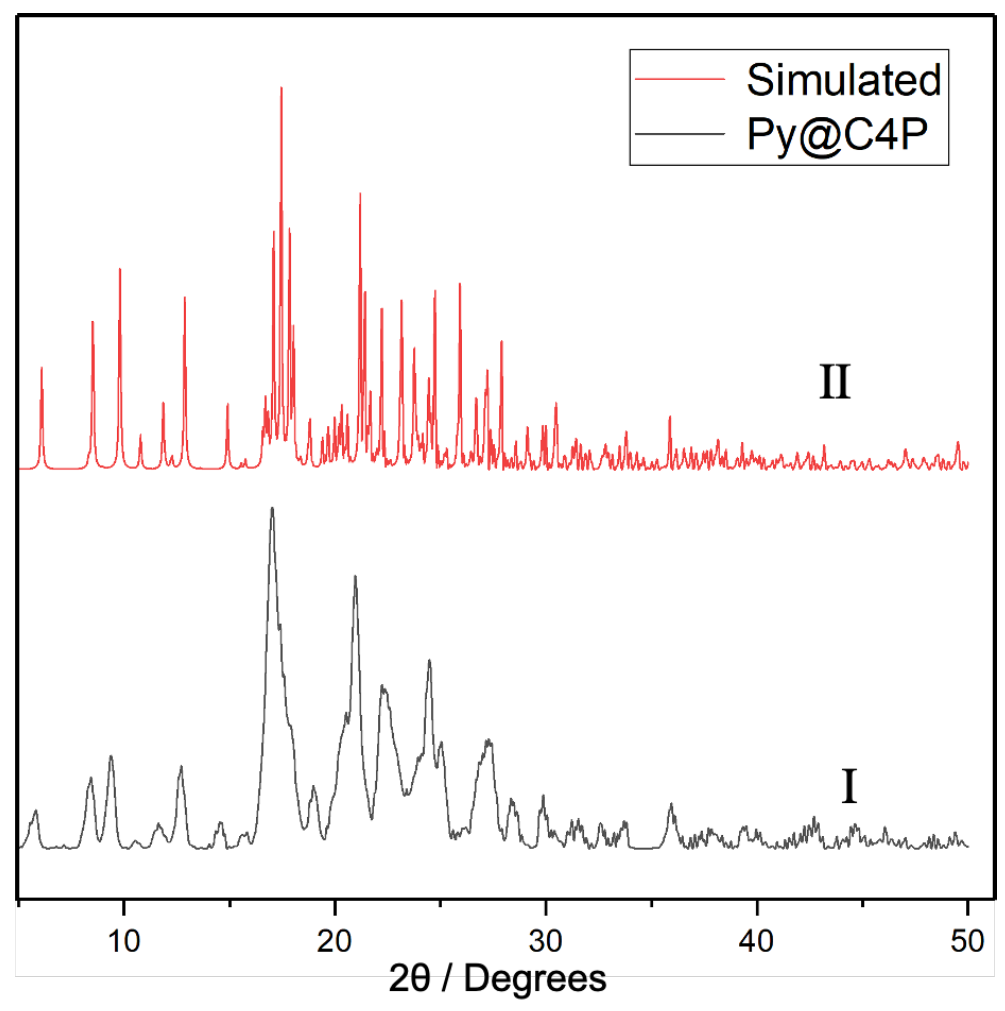

Figure S9. Powder X-ray diffraction pattern of (I) Py@C4P; (II) simulated Py@C4P 


\section{Single-component Tol/Py adsorption experiments}

${ }^{1} \mathrm{H}$ NMR spectroscopic experiments were performed after vapor sorption by dissolving $\mathbf{C 4 P}$ in DMSO- $d_{6}$.

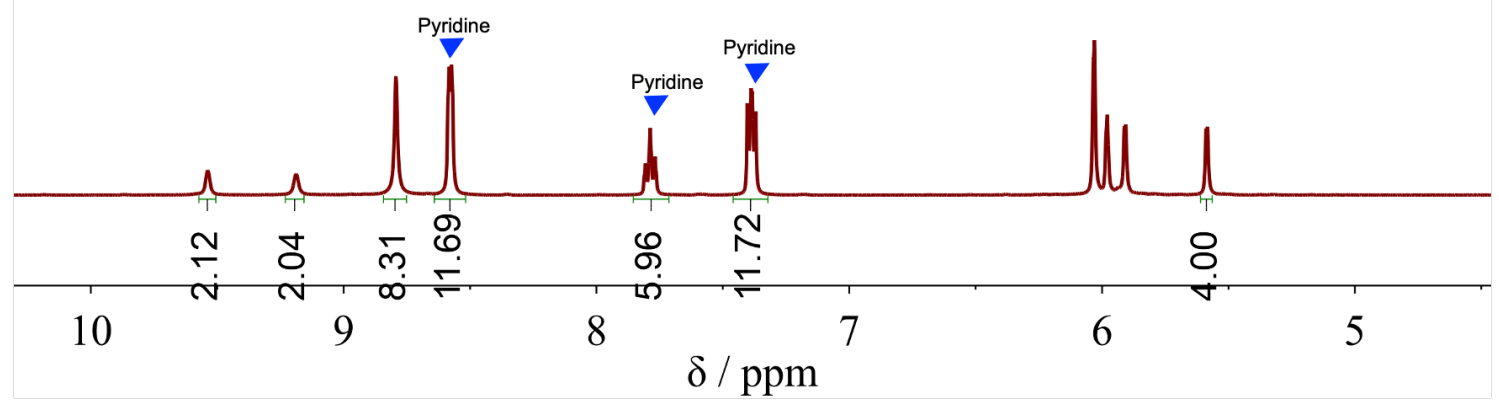

Figure S10. ${ }^{1} \mathrm{H}$ NMR spectrum $\left(400 \mathrm{MHz}, \mathrm{DMSO}-d_{6}, 25^{\circ} \mathrm{C}\right)$ of $\mathbf{C 4 P}$ after sorption of Py vapor for $6 \mathrm{~h}$.

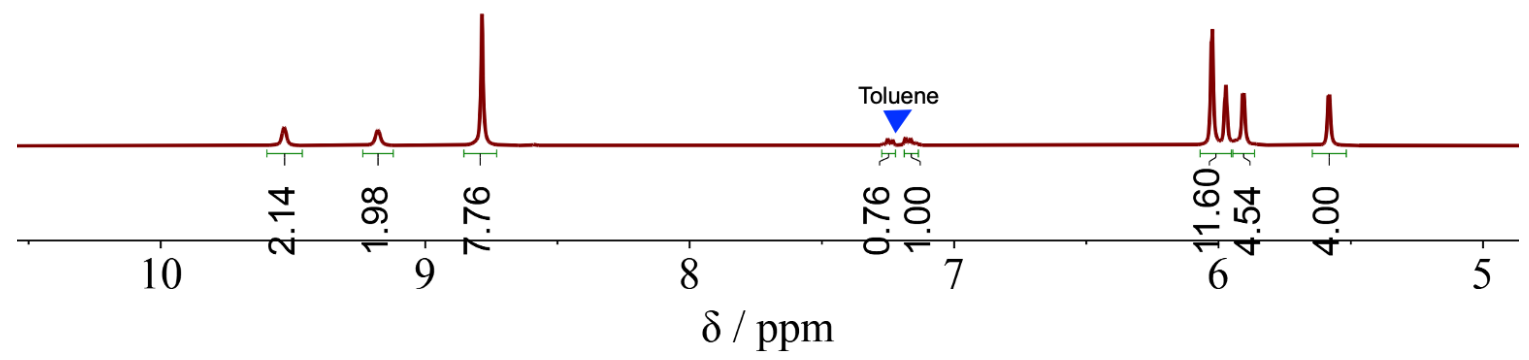

Figure S11. ${ }^{1} \mathrm{H}$ NMR spectrum $\left(400 \mathrm{MHz}, \mathrm{DMSO}-d_{6}, 25{ }^{\circ} \mathrm{C}\right)$ of $\mathbf{C 4 P}$ after sorption of Tol vapor for $6 \mathrm{~h}$. 


\section{Uptake from a toluene/pyridine mixture by C4P}

For each vapor phase experiment, an open $5 \mathrm{~mL}$ vial containing $20 \mathrm{mg}$ of guest-free $\mathbf{C 4 P}$ adsorbent was placed in a sealed $20 \mathrm{~mL}$ vial containing $3 \mathrm{~mL}$ of a equimolar mixture of toluene and pyridine. Uptake by $\mathbf{C 4 P}$ was measured by completely dissolving the crystals and measuring the ratio of Tol or Py to $\mathbf{C 4 P}$ by means of ${ }^{1} \mathrm{H}$ NMR spectroscopy. The relative uptake amount of toluene or pyridine in $\mathbf{C 4 P}$ was also measured gas chromatography by heating the crystals in to release the adsorbed vapor using. Before the measurements, the crystals were air-dried to remove the surfacephysically adsorbed molecules.

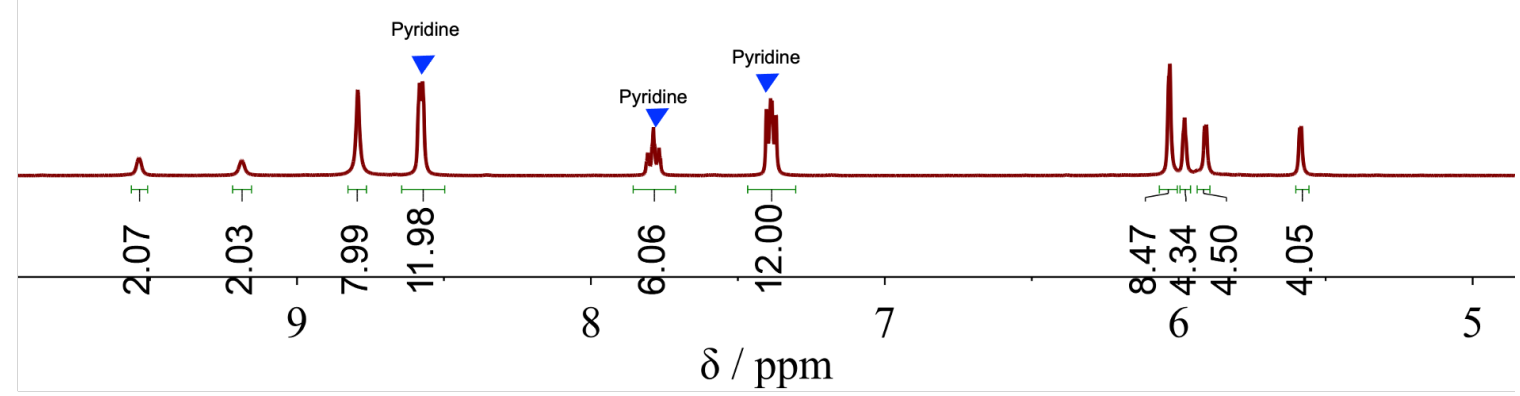

Figure S12. ${ }^{1} \mathrm{H}$ NMR spectrum (400 MHz, DMSO- $\left.d_{6}, 25{ }^{\circ} \mathrm{C}\right)$ of $\mathbf{C 4 P}$ after a 6 hour sorption experiment involving a mixture of Tol and Py. 

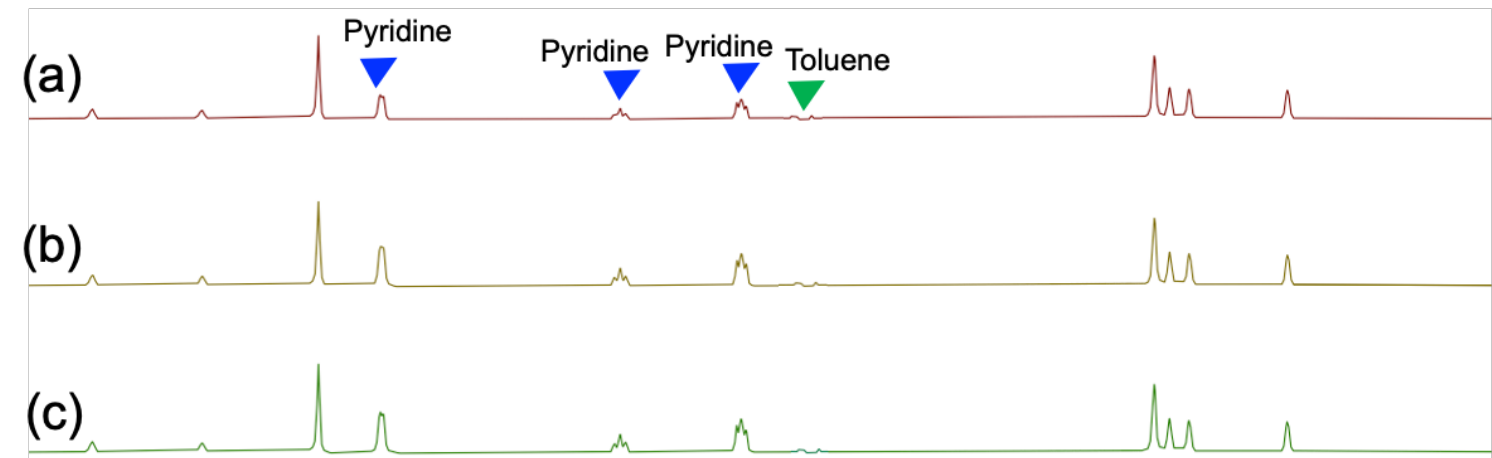

(d)
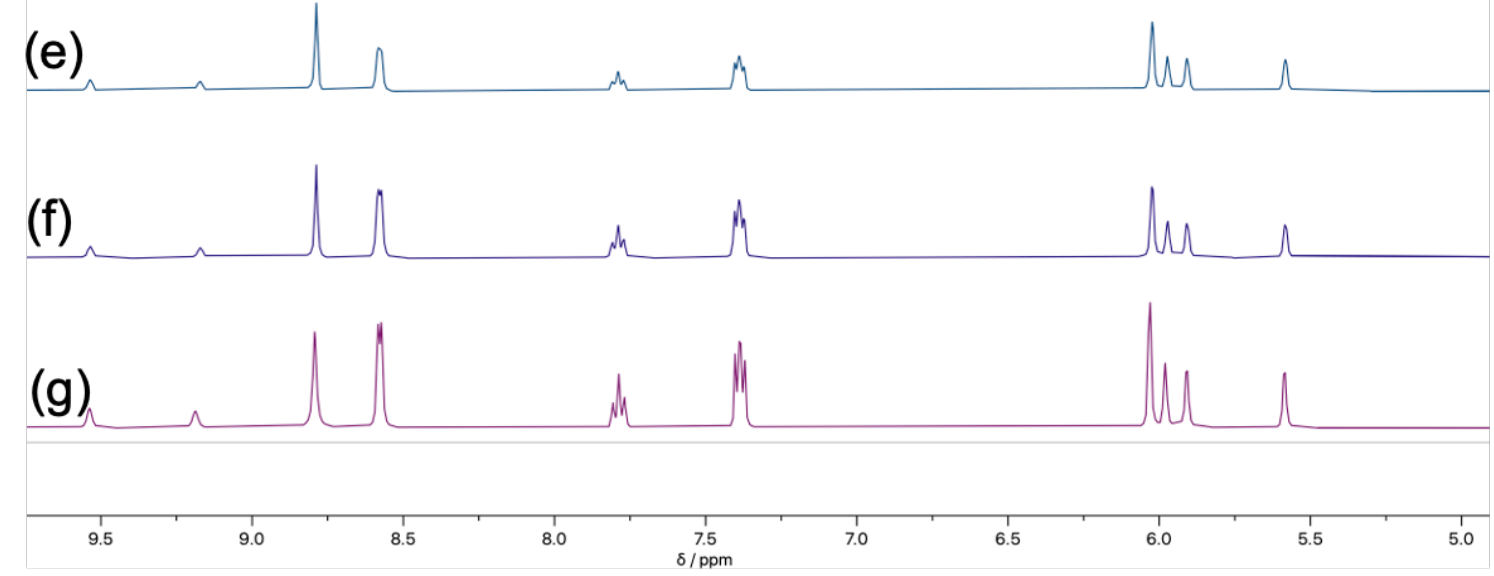

Figure S13. Time-dependent ${ }^{1} \mathrm{H}$ NMR spectra (400 MHz, DMSO- $d_{6}, 298 \mathrm{~K}$ ) of C4P after sorption of Py/Tol (23:77 molar ratio) vapor mixture: (a) 1.0 h; (b) 2.0 h; (c) 2.5 h; (d) 3.0 h; (e) 3.5 h; (f) $4.0 \mathrm{~h} ;(\mathrm{g}) 5.0 \mathrm{~h}$. 


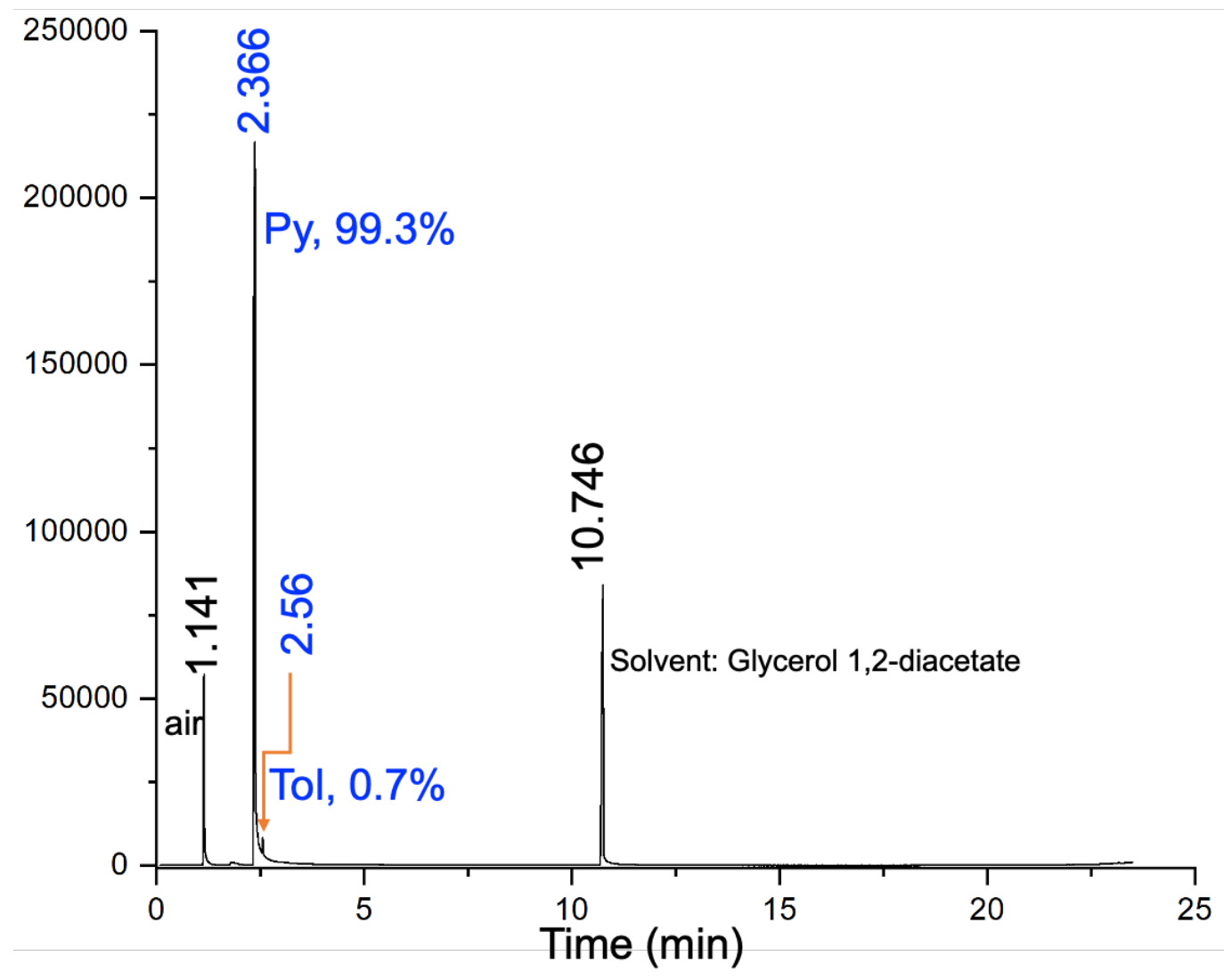

Figure S14. Relative uptake of pyridine and toluene vapors by C4P from an equimolar Py/Tol mixture after a 6 hour adsorption experiment as determined using gas chromatography. 


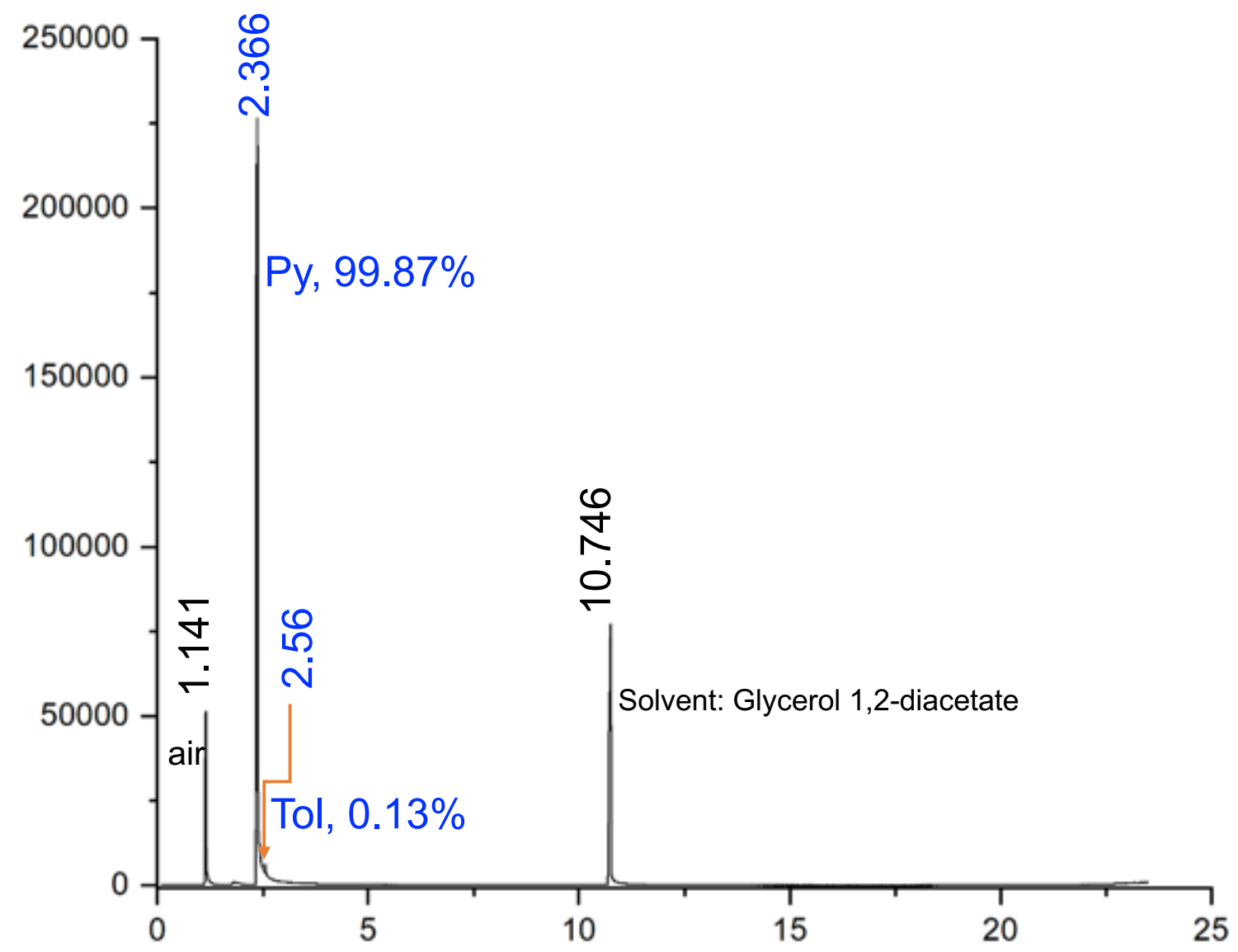

Figure S15. Relative uptake of vapors from a Tol/Py mixture (77:23 by mole ratio) by $\mathbf{C 4 P}$ after a 6 hour adsorption experiment as determined using gas chromatography. 


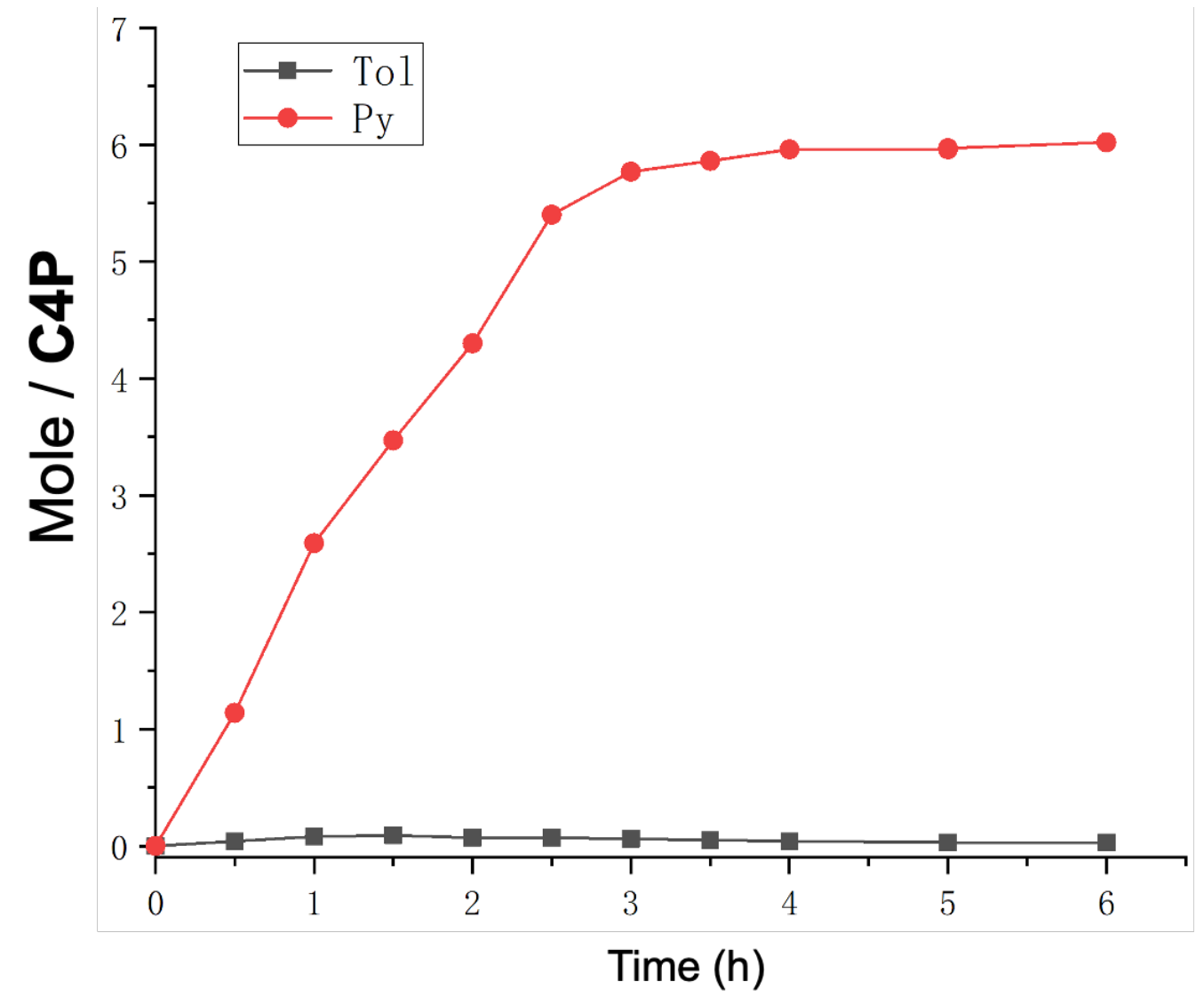

Figure S16. Time-dependent C4P solid-vapor sorption plot for Tol/Py (77:23 by mole ratio) mixture vapor. 


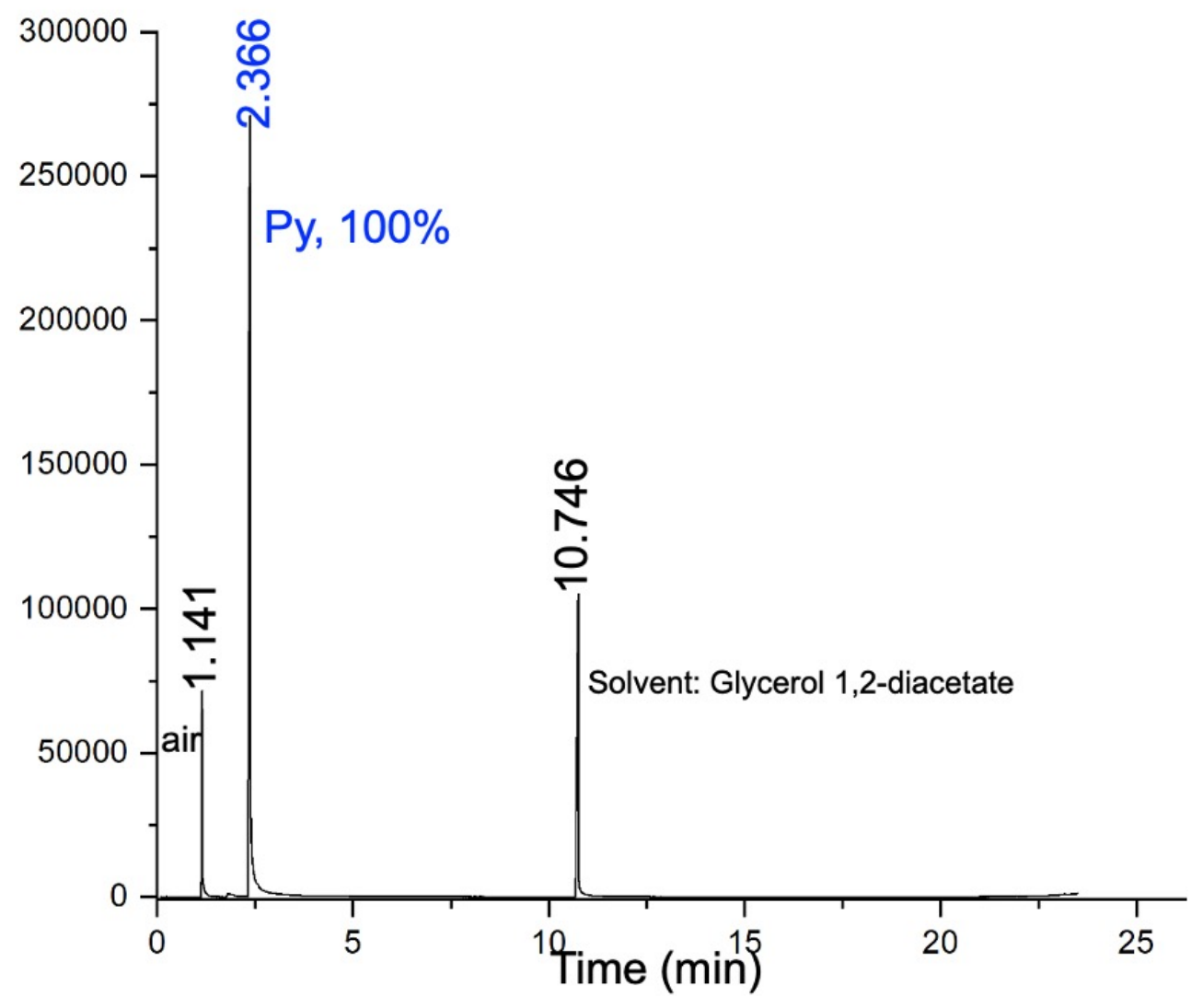

Figure S17. Relative uptake of the Tol/Py mixture (v:v = 100:1) adsorbed by $\mathbf{C 4 P}$ (after adsorption of this mixture vapor for 6 hours) using gas chromatograph 
8. Dioxane removal from a dioxane/water mixture by $\mathbf{C 4 P}$

\begin{tabular}{ll} 
(a) & \\
(b) & \\
\hline
\end{tabular}

(c)

$6 \mathrm{~h}$

(d)

$12 \mathrm{~h}$

(e)

(f) $36 \mathrm{~h}$

$\begin{array}{llllll}7.0 & 6.0 & 5.0 & 4.0 & 2.0 & 1.0 \\ & & & \end{array}$

Figure S18. Time-dependent partial ${ }^{1} \mathrm{H}$ NMR spectra (400 MHz, $\left.\mathrm{D}_{2} \mathrm{O}, 298 \mathrm{~K}\right)$ of a 1,4-dioxane- $\mathrm{D}_{2} \mathrm{O}$ solution upon addition of C4P. (Initial dioxane concentration: $6 \mathrm{mM}$.) 


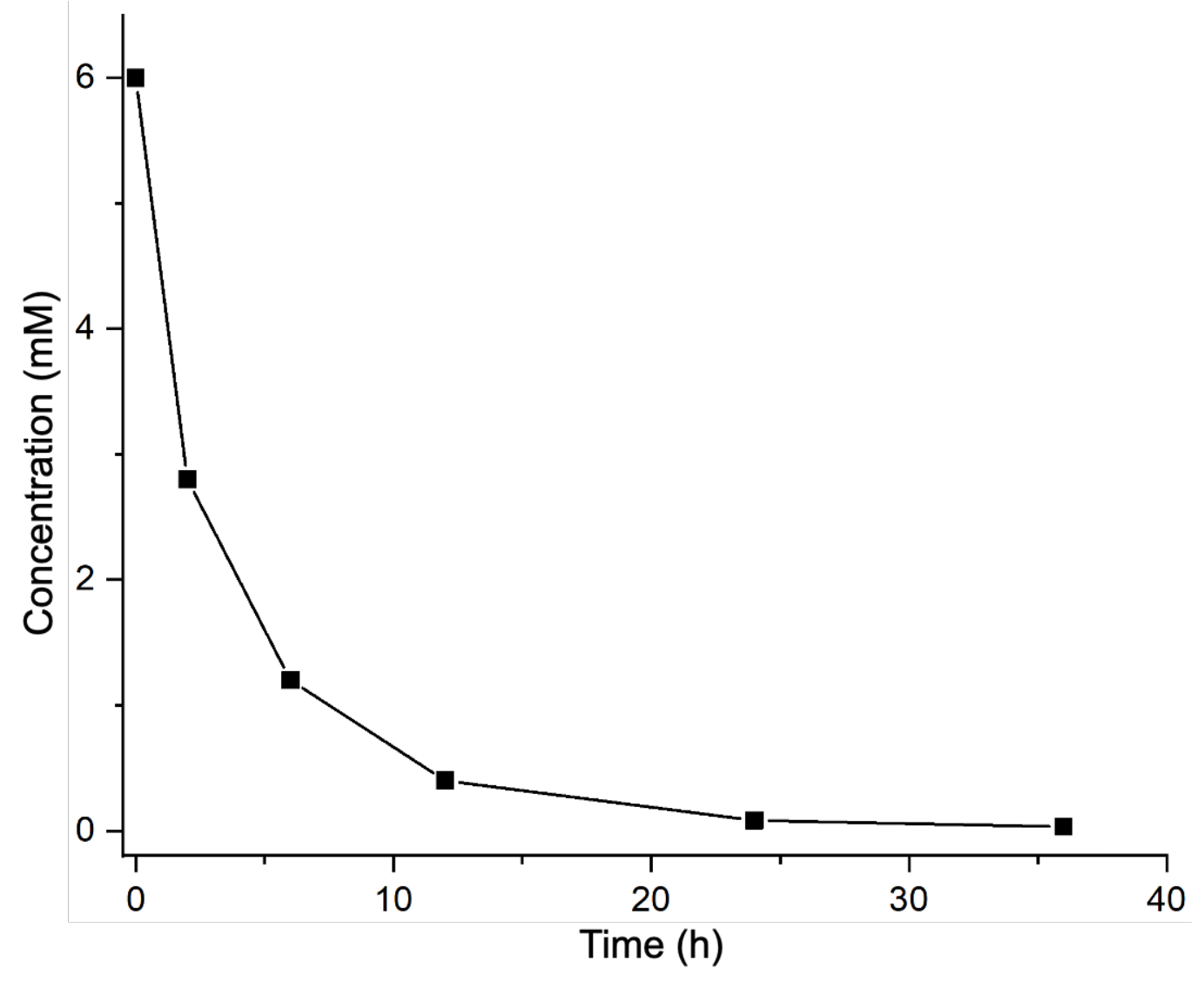

Figure S19.Time-dependent plot of the C4P-induced change in dioxane concentration in $\mathrm{D}_{2} \mathrm{O}$ corresponding to the studies in Figure S18. 


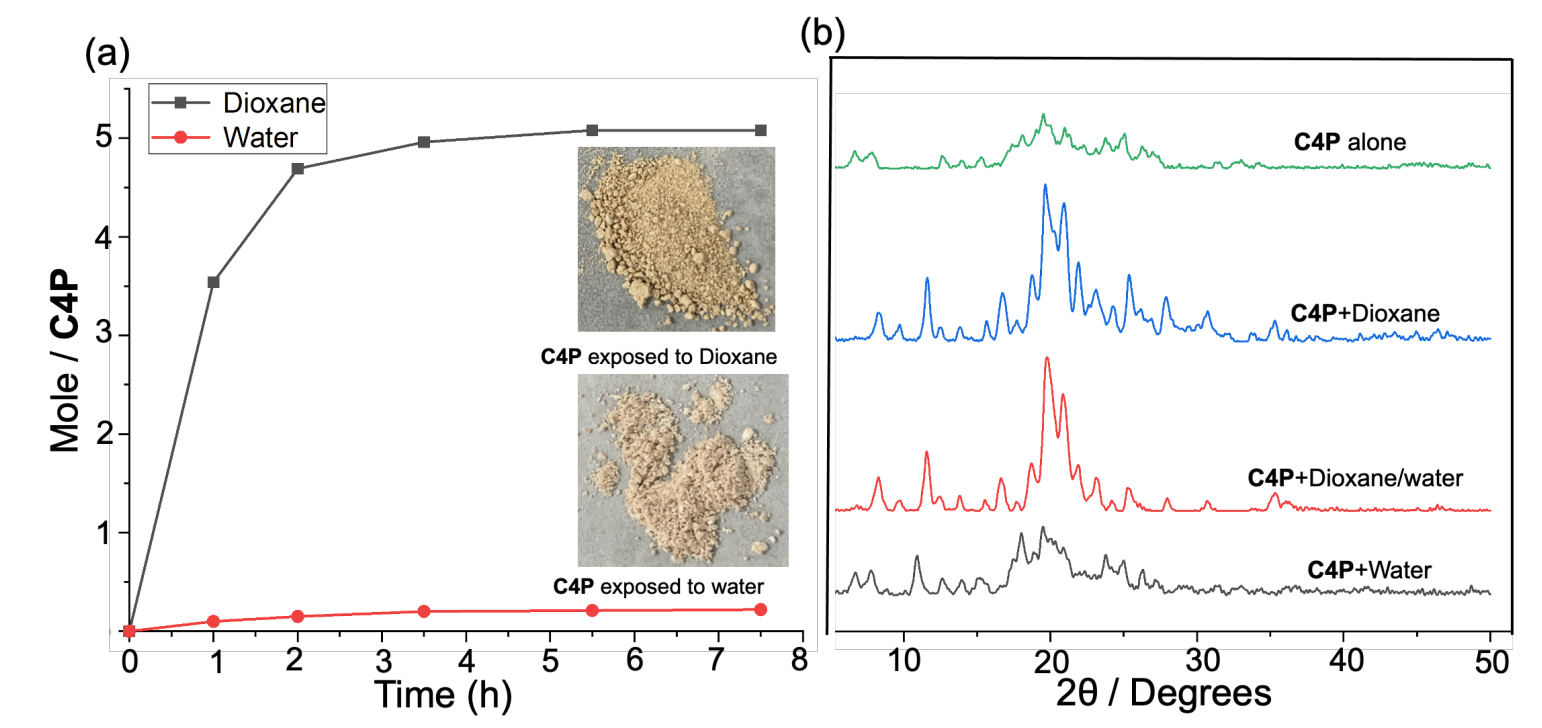

(b)

Figure S20. (a) Time-dependent C4P solid-vapor sorption isotherms for a dioxane/water vapor mixture (1,4-dioxane/water 47.2 : 52.8 molar ratio); Inserts show photographs of $\mathbf{C 4 P}$ crystals after exposure to 1,4-dioxane (top) or water (bottom) vapor for $8 \mathrm{~h}$. (b) PXRD patterns of C4P (green line) after activation by heating at $80{ }^{\circ} \mathrm{C}$ for 12 hours under vacuum, (blue line) after adsorption of 1,4-dioxane vapor, (red line) after adsorption of 1,4-dioxane/water mixture vapor, and (black line) after adsorption of water vapor. 


\section{Recyclability of C4P}

An open 5 mL vial containing 20 mg of Py@C4P or dioxane@C4P was desolvated by heating under vacuum at $120^{\circ} \mathrm{C}$ overnight.

(a)

(b)

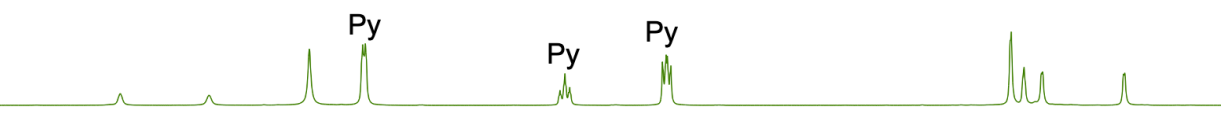

(c)

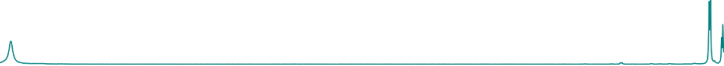

(d)

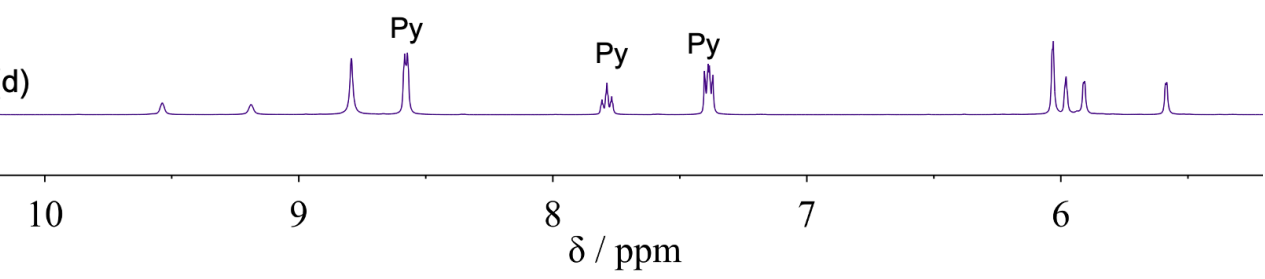

Figure S21. ${ }^{1} \mathrm{H}$ NMR spectra (400MHz, DMSO- $\left.d_{6}, 298 \mathrm{~K}\right)$ : (a) as-prepared form of C4P; (b) C4P after adsorption of Py; (c) Py@C4P after removal of Py; (d) desolvated Py@C4P after re-adsorption of Py vapor. 
(a)

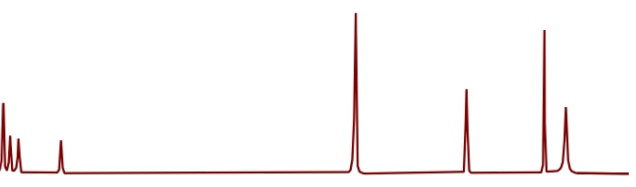

(b)

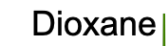

(c)

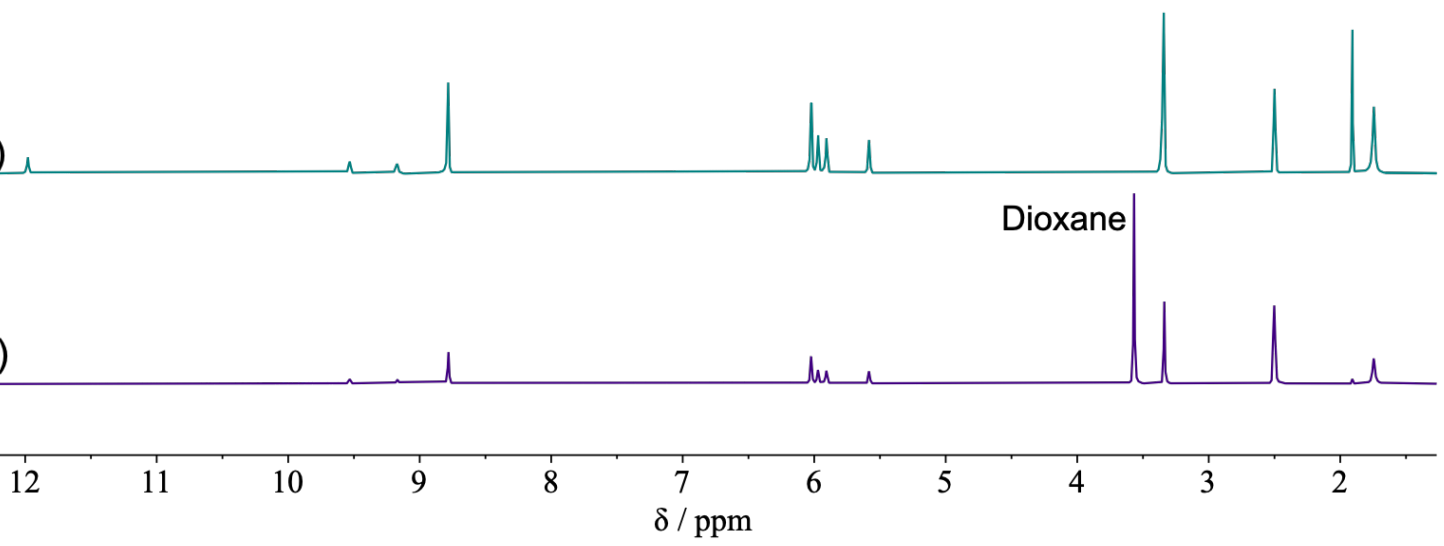

(d)

Figure S22. ${ }^{1} \mathrm{H}$ NMR spectra (400 MHz, DMSO- $d_{6}, 298 \mathrm{~K}$ ): (a) As-prepared form of C4P; (b) C4P after adsorption of dioxane; (c) dioxane@C4P after removal of dioxane; (d) desolvated dioxane@C4P after re-adsorption of dioxane vapor.

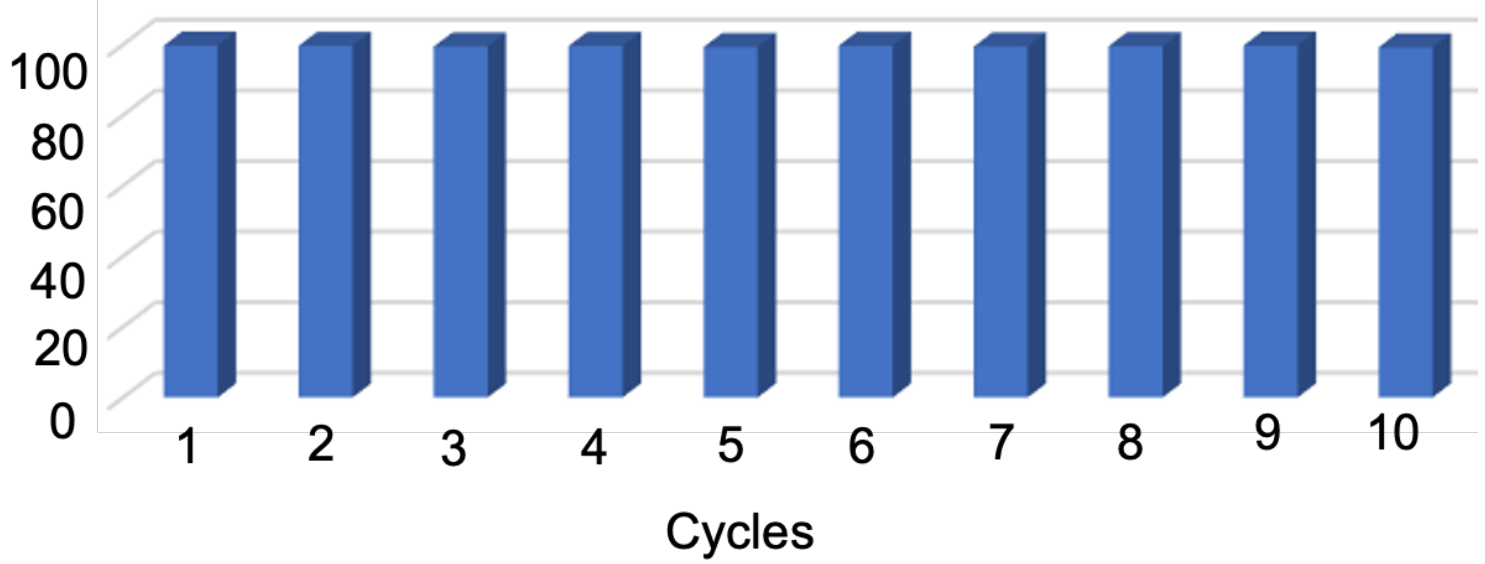

Figure S23. Recyclability of C4P with relative uptake of Py in Tol/Py (77:23 molar ratio) mixture by $\mathbf{C} 4 \mathbf{P}$ with $6 \mathrm{~h}$ uptake cycles. 


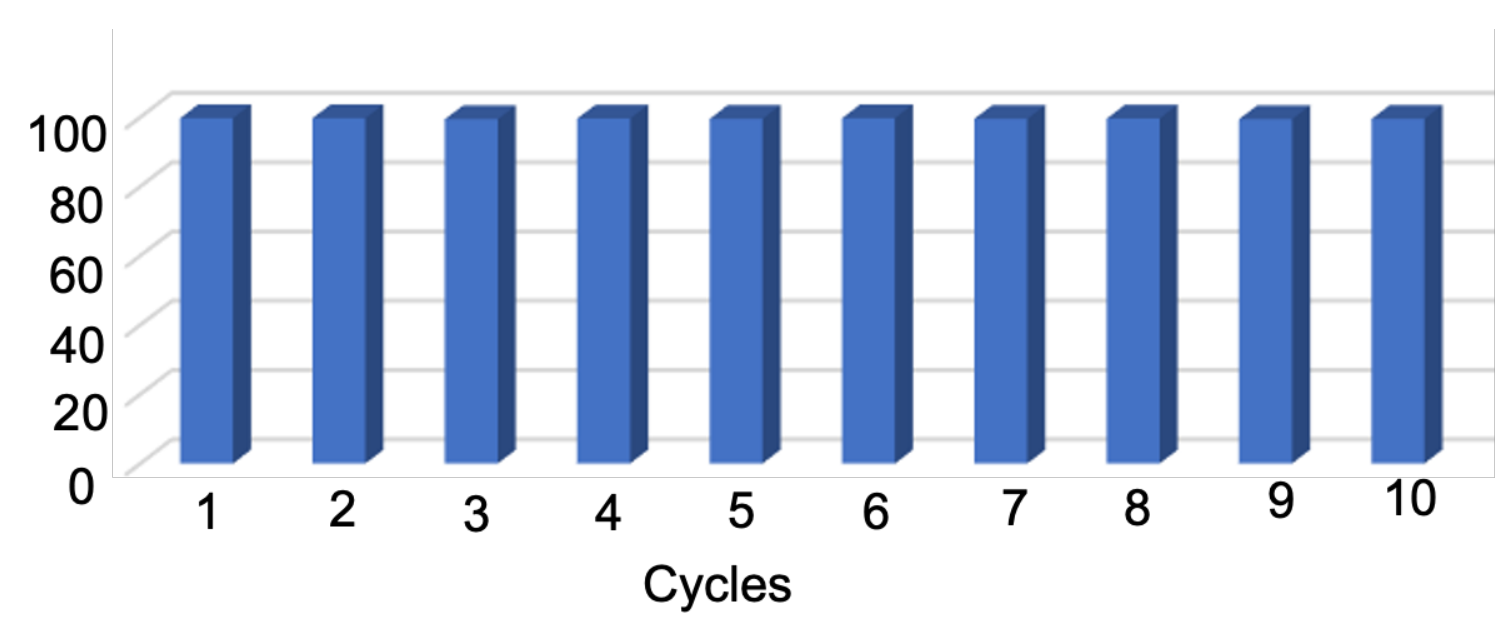

Figure S24. Recyclability of C4P with relative uptake of dioxane in dioxane/water (47.2:52.8 molar ratio) mixture by $\mathbf{C 4 P}$ with $8 \mathrm{~h}$ uptake cycles.

10. References:

1) CrysAlisPro. Rigaku Oxford Diffraction, CrysAlicPro Software System 2019, 1.171.40.53.

2) Sheldrick, G. M. SHELXT.; A program for crystal structure solution. Acta Cryst. 2015, A71, 3-8.

3) Sheldrick, G. M.; SHELXL-2016/6.; Program for the Refinement of Crystal Structures. Acta Cryst. 2015, C71, 9-18.

4) Spek, A. L. PLATON, A Multipurpose Crystallographic Tool. Utrecht University, The Netherlands. Acta Cryst. 2009, D65, 148-155.

5) Dolomanov, O. V., Bourhis, L. J., Gildea, R. J., Howard, J. A. K.; Puschmann, H. A. OLEX2. Complete Structure Solution, Refinement and Analysis Program. J. Appl. Cryst. 2012, 42, 339-341.

6) Farrugia, L. J. J. WinGX 1.64.. An Integrated System of Windows Programs for the Solution, Refinement and Analysis of Single Crystal X-ray Diffraction Data. Appl. Cryst. 1999, 32. 837-838.

7) Sluis, P. v. d.; Spek, A. L. SQUEEZE. Acta Cryst. 1990, A46, 194-201. 
8) International Tables for X-ray Crystallography, 1992, Vol. C, Tables 4.2.6.8 and 6.1.1.4, A. J. C. Wilson, editor, Boston: Kluwer Academic Press.

9) Sheldrick, G. M. SHELXTL/PC (Version 5.03). Siemens Analytical X-ray Instruments, Inc., Madison, Wisconsin, USA. 1994. 